\title{
Degenerative changes in aortic root allografts placed in the right ventricular outflow tract of growing puppies
}

\author{
UNG-GILL JEONG ${ }^{2}$, ABDULA. KHA N", \\ GERALD FIN E ${ }^{1}$, GORDON M. FOLGER, J r ${ }^{3}$, , \\ and LORENZO GONZALEZ-LA V I N ${ }^{4}$ \\ Divisions of Pathology ${ }^{1}$, Thoracic Surgery ${ }^{2}$, and Pediatric Cardiology ${ }^{3}$, Henry Ford Hospital, \\ Detroit, Michigan and the Division of Cardiothoracic Surgery, \\ Michigan State University, East Lansing, Michigan, USA
}

\begin{abstract}
Jeong, U-G., Khan, A. A., Fine, G., Folger, G. M., Jr., and Gonzalez-Lavin, L. (1976). Thorax, 31, 757-764. Degenerative changes in aortic root allografts placed in the right ventricular outflow tract of growing puppies. Differently prepared aortic root allografts were implanted in the right ventricular outflow tract of growing puppies to determine the site of origin and progress of degenerative changes in these conduits. The three preparations assessed were as follows: group A, fresh and sterile grafts; group B, antibiotic sterilized grafts in nutrient medium; and group $\mathrm{C}$, beta-propiolactone sterilized grafts. Although calcification of the aortic wall occurred in all groups, the aortic leaflets were minimally affected. A correlation between viability and lack of calcification and between viability and long-term function is emphasized.
\end{abstract}

Since 1966, when Ross and Somerville first used an aortic root allograft to treat a patient with pulmonary atresia successfully, the use of valved conduits for the correction of certain severe heart malformations has become established. This pioneer effort was followed by successful treatment of truncus arteriosus, transposition of the great arteries with ventricular septal defect and pulmonary stenosis, and tricuspid atresia (McGoon, Wallace, and Danielson, 1973; Fontan and Baudet, 1971). As these procedures allow anatomical correction of the heart malformation and are usually performed in children, the long-term function of the valved conduit is of the utmost importance.

There is continued disagreement about the behaviour of these allografts. A number of authors have reported severe calcification, stenosis, and pseudoaneurysm formation when preserved allografts were used (Merin and McGoon, 1973; Park et al., 1973; Kaplan et al., 1974), while others have reported good to excellent results when fresh grafts were used (Moore, Martelli, and Ross, 1976).
Therefore, a reassessment of the methods of graft preparation seemed justified in order to detect the site and timing of degenerative changes and, hence, help to devise a more suitable valve conduit. In this experimental work, differently prepared aortic root allografts were placed in the right ventricular outflow tract of growing puppies.

\section{MATERIAL AND METHODS}

Twenty-three pairs of non-litter puppies, 8 to 10 weeks old and weighing 7 to $14 \mathrm{lb}(3.2$ to $4.5 \mathrm{~kg})$, were used in this study. Each pair was matched as to age and weight. One member of the pair was the donor of the aortic root allograft, while the other served as the recipient. The puppies were divided into three groups according to the method of allograft preparation.

Group A consisted of 10 pairs of dogs. The recipient members of this group received fresh aortic root allografts which were obtained under sterile conditions and placed in recipient's heparinized blood at room temperature for approximately 30 minutes before implantation. 
Group B consisted of eight pairs of dogs. The donor grafts were first placed in nutrient medium with $10 \%$ calf serum containing a mixture of antibiotics (Table). They were stored at $4^{\circ} \mathrm{C}$ for periods of up to seven weeks before being used.

Group C consisted of five pairs of dogs. The grafts were sterilized with $0.5 \%$ beta-propiolactone before preservation in nutrient medium with $10 \%$ calf serum containing a mixture of antibiotics (Table). They were stored at $4^{\circ} \mathrm{C}$ for periods of up to six weeks before transplantation.

T A B L E

ANTIBIOTICS USED FOR STERILIZATION OF AORTIC ROOT \begin{tabular}{l|c}
\multicolumn{2}{c|}{ ALLOGRAFTS BEFORE INSERTION } \\
\hline \multicolumn{1}{c|}{ Antibiotic } & $\begin{array}{c}\text { Concentration in } \\
\text { Storage Medium }\end{array}$ \\
\hline Gentamycin & $4 \mathrm{mg} / \mathrm{ml}$ \\
Methicillin & $10 \mathrm{mg} / \mathrm{ml}$ \\
Erythromycin-lactobioate & $6 \mathrm{mg} / \mathrm{ml}$ \\
Nystatin & $2500 \mathrm{units} / \mathrm{ml}$ \\
\hline
\end{tabular}

Sterility of allografts in groups B and C was determined by culturing pieces of the aortic wall for aerobic, anaerobic, and fungal organisms after 72 hours of exposure to the antibiotic-containing medium and again at the time of implantation. Viability of the graft was assessed by histochemical enzyme stains for lactate dehydrogenase and DPNH diaphorase (Fine, Morales, and Scerpella, 1966).

OPERATIVE TECHNIQUE The allograft valve and ascending aorta were dissected away from the donor heart. The allograft was then either immediately used or preserved, according to its group assignment.

Right ventricular outflow tract (RVOT) reconstruction was performed through a left thoracotomy without the aid of cardiopulmonary bypass. After implantation of the allograft, the main pulmonary artery was ligated so as to allow all the blood to flow through the valved conduit (Fig. 1). Right ventricular and pulmonary artery pressures were measured both before and after the insertion of the allograft. There were no significant differences in the preoperative and postoperative values of these measurements.

\section{RESULTS}

SURVIVAL DATA In group A, four dogs died from 3 to 33 days after operation. On gross examination

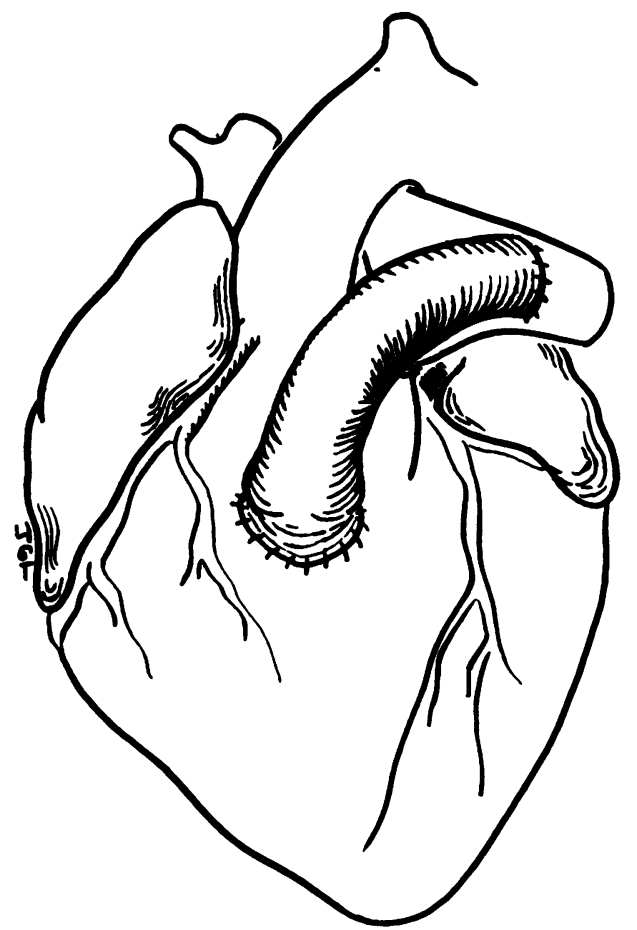

FIG. 1. Diagram outlining the method for implanta- $\frac{\mathscr{Q}}{\stackrel{0}{\circ}}$ tion of the allograft in the right ventricular outflow $\cong$ tract.

these four dogs did not demonstrate any calcification or stenosis of the allografts. The causes of death were thrombosis, pneumonia, and haemor- $\frac{\mathrm{O}}{2}$ rhage. Six dogs either died or were sacrificed over $x$ a period of 48 to 288 days after operation. All $\frac{0}{3}$ demonstrated some degree of calcification of the aortic root allograft, and some of them, mainly the longer survivors, showed progressive encroachment by calcific process into the sinus of Valsalva $\frac{\text { S }}{5}$ and finally into the base of the aortic leaflets. In $\frac{D}{2}$ three animals, stenosis of the proximal anastomosis was present due to cicatrization and calcifica- No tion. Dogs receiving fresh grafts had the longest survival time and the best functional results.

In group B, five dogs died in 4 to 32 days, and $\mathrm{W}$ none of these showed calcification. Pneumonia was the main cause of death. Three dogs survivinge 43 to 66 days all demonstrated patterns of calcification similar to those observed in group A.

In group $C$, two dogs dying in less than 19 days $\frac{7}{7}$ showed no calcification while it was present in $\frac{\mathrm{O}}{\mathbb{D}}$ three dogs surviving 74 to 90 days. In this group calcification was more marked. 
GROSS FINDINGS All grafts in animals surviving more than 33 days, regardless of whether they received fresh or preserved allografts, demonstrated thickening, loss of flexibility, and the presence of grittiness of the aortic wall due to calcification. Thickening and rigidity were also noted at the base of the grafted aortic valve annulus. In contrast to these findings, calcification was present only rarely, and then to a minimal degree, in the valve leaflets, which remained thin, soft, and pliable. Thrombosis of the aortic root allograft was observed in some instances, the earliest 15 days after operation.

Cardiomegaly was observed in most animals three to four weeks after RVOT reconstruction. In dogs surviving more than 36 days, the hearts resembled those of patients with severe pulmonary stenosis. The right ventricular wall was thickened and the proximal anastomosis showed marked narrowing due to cicatrization and calcification.
The valve ring at necropsy was smaller than the original diameter at the time of surgery. The average internal diameter of the allograft decreased from a value of $9.1 \mathrm{~mm}$ at the time of operation to a value of $6.6 \mathrm{~mm}$ at the time of necropsy.

HISTOLOGICAL FINDINGS Microscopic examinations of the allografts were performed from 4 to 228 days after allograft insertion in the RVOT. Disappearance of the cellular components of the aortic wall was observed as early as four days after the operation. The surviving cells were generally in the innermost one-third of the aortic wall and only rarely observed in the outer portions (Fig. 2). These changes were delineated by a variety of stains, ie, haematoxylin and eosin, Masson trichrome, and histochemical enzyme stains for lactate dehydrogenase and EPNH diaphorase.

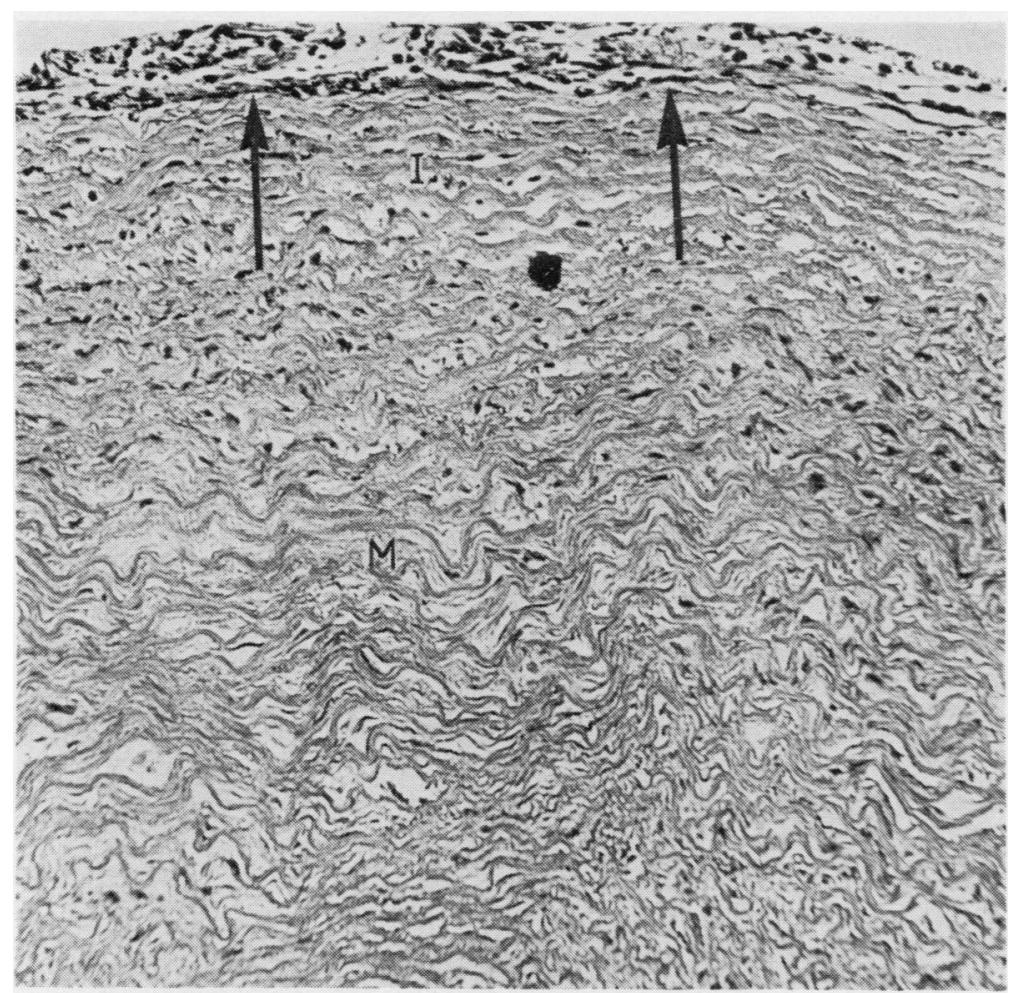

FIG. 2. Fresh graft in place for 16 days. There is focal increase of endothelial and mesenchymal cells (arrows). Mid-portion of the aortic wall $(M)$ shows loss of cellular elements and separation of the elastic fibres, while these changes are minimal in the innermost portion (I) of the graft. Haematoxylin and eosin $\times 150$. 


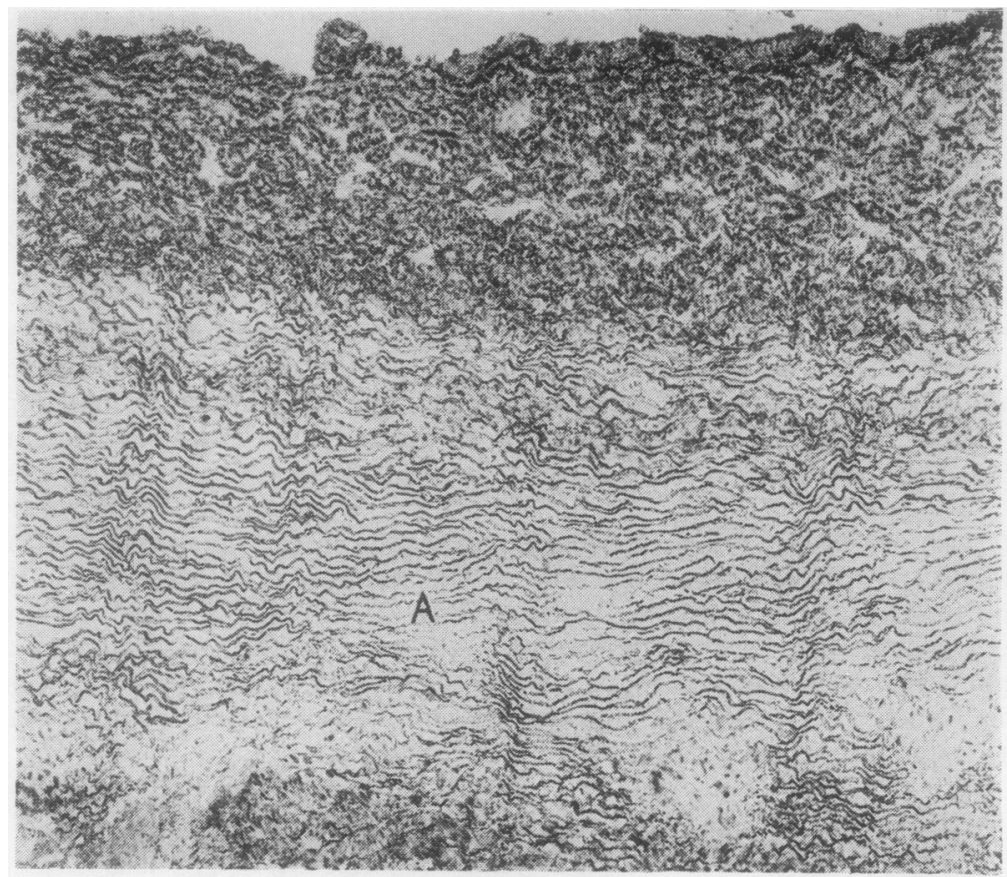

FIG. 3. Fresh graft in place for 16 days. Cellular loss and separation of elastic fibres in mid-portion of aorta $(A)$ are in sharp contrast to the adjacent wall and the recipient's aorta (Fig. 4). Lactic dehydrogenase $\times 70$.

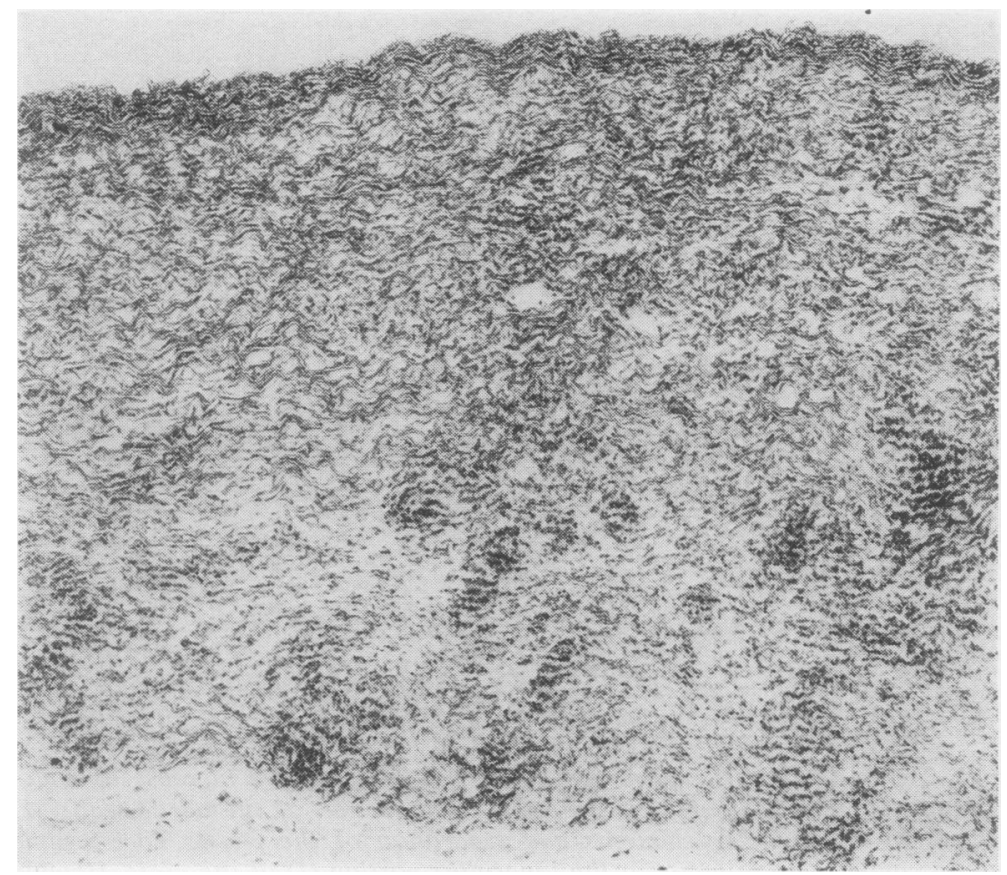

FIG. 4. Recipient animal's aorta. Lactic dehydrogenase $\times 70$. 


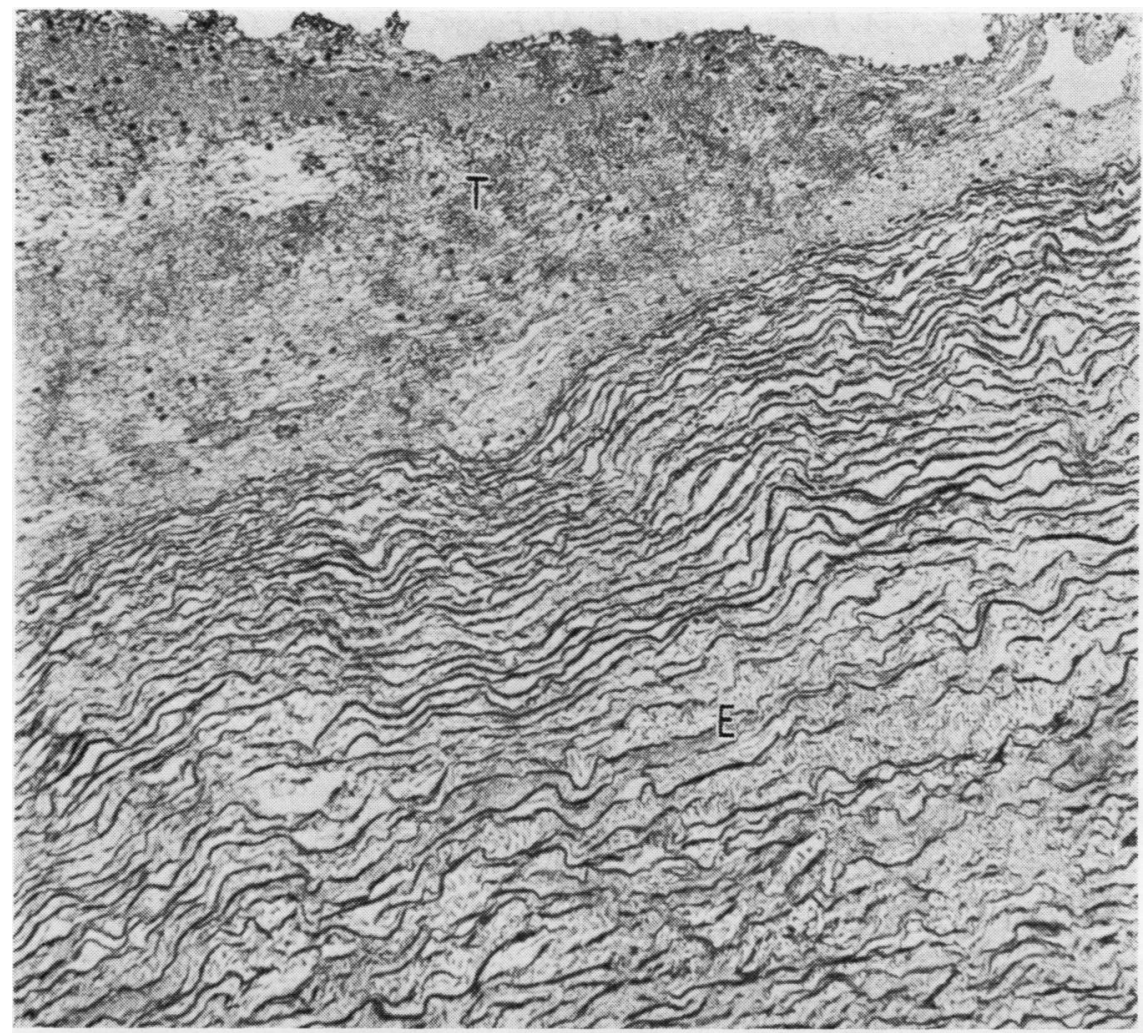

FIG. 5. Beta-propiolactone graft in place for 19 days. Separation and loss of elastic fibres is shown in area $E$. Organizing thrombus $(T)$ is also demonstrated. Calcification is not apparent. Haematoxylin and eosin $\times 150$.

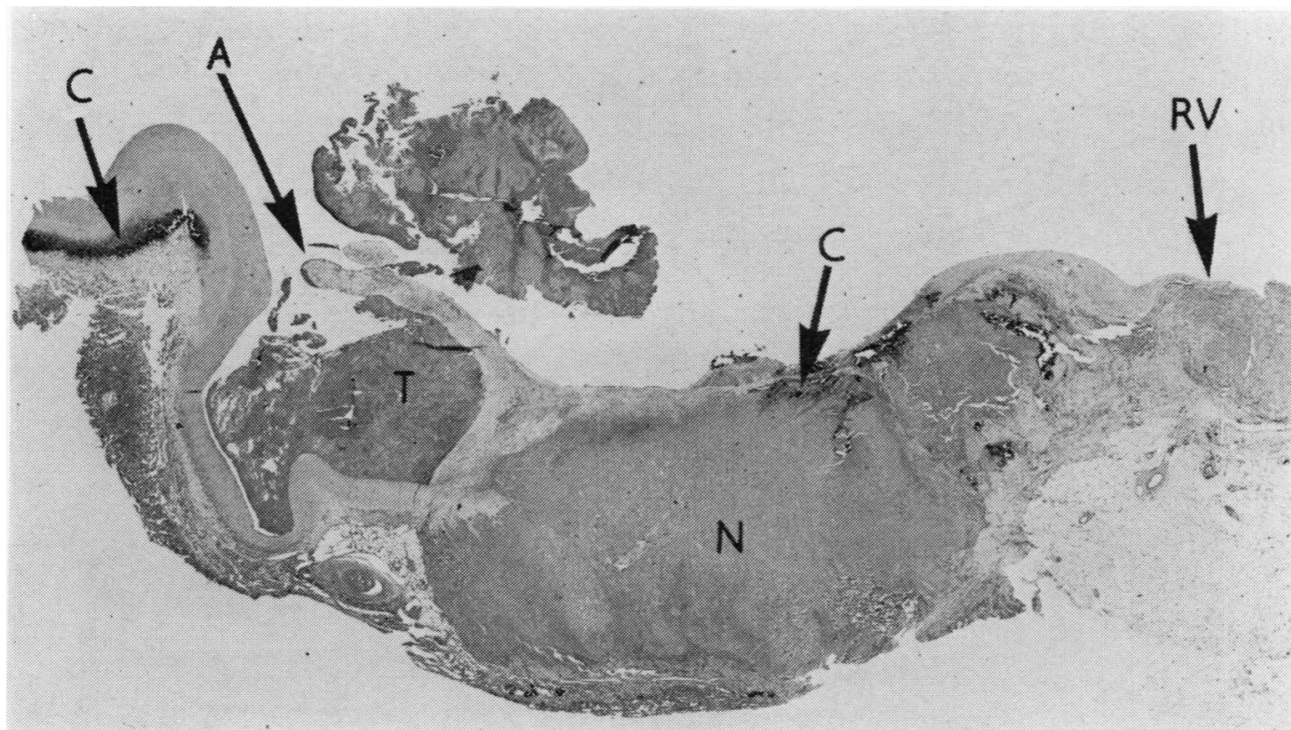

FIG. 6. Same graft as in Figure 2. Early calcification $(C)$ is shown. Donor left ventricular muscle (N) at the base of the valve is necrotic. Aortic cusp $(A)$ is thicker than normal. (T) thrombus and $(R V)$ recipient's right ventricular muscle. Von Kossa $\times 7$. 


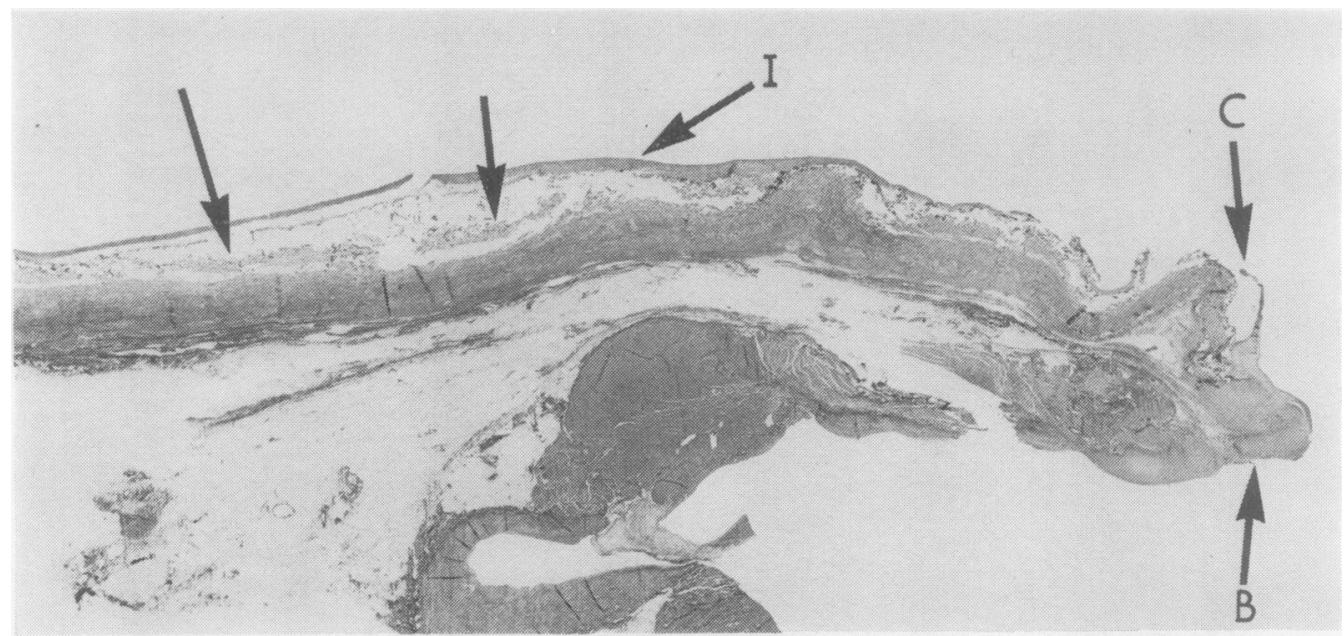

FIG. 7. Beta-propiolactone graft in place for 77 days. Calcification (unlabelled arrows) spares the intimal surface (I). Aortic cusp $(C)$ has remained delicate, but the base of the valve $(B)$ is thickened by fibrous tissue. Haematoxylin and eosin $\times 6$.

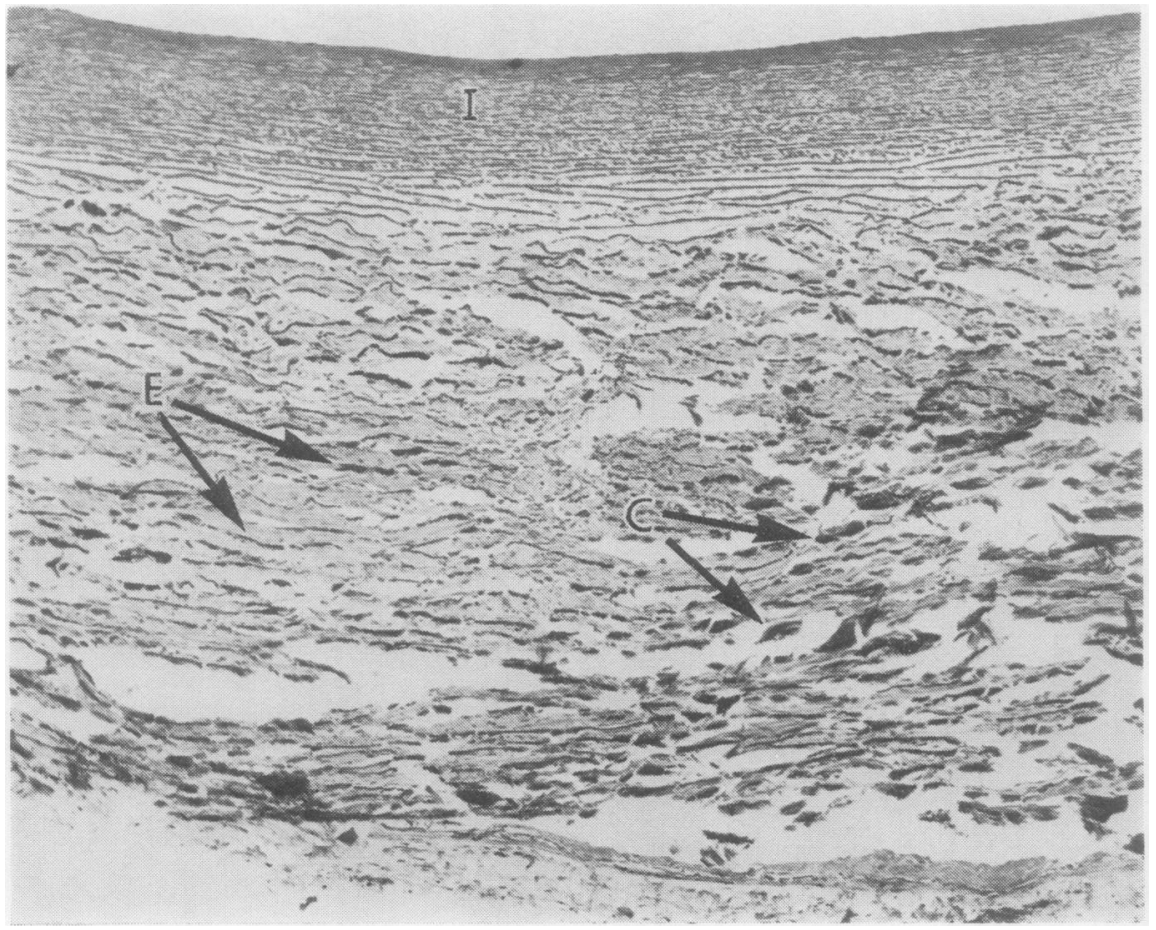

FIG. 8. Same graft as in Figure 7. Irregular calcium deposits $(C)$ are present in the aortic wall. Extent of calcification in area $E$ is not easily seen. Intimal aspect of the aorta (I) is spared from calcification. Haematoxylin and eosin $\times 90$. 


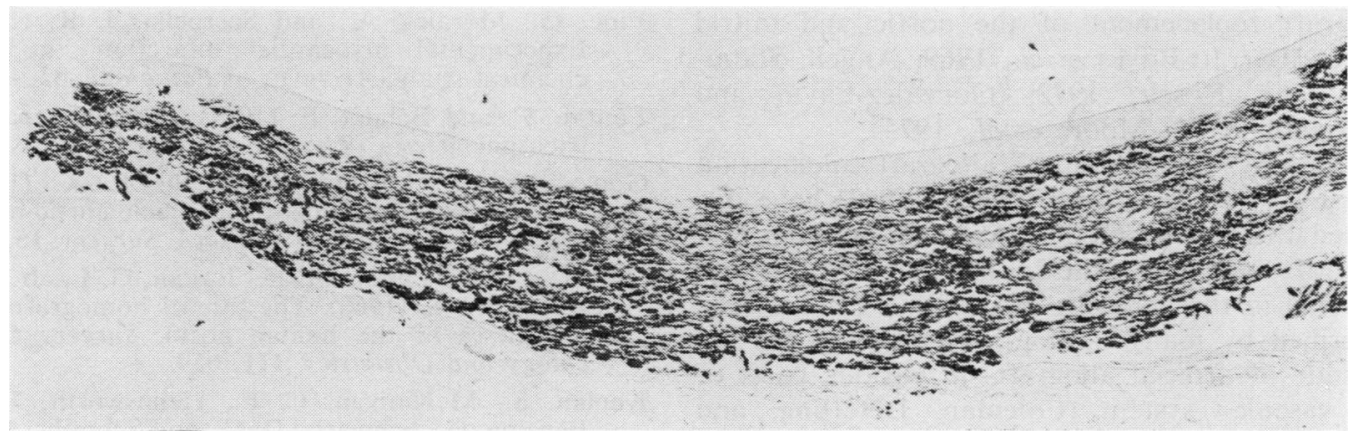

FIG. 9. Area $E$ of Figure 8 shows more extensive calcification with special stain. Von Kossa $\times 22$.

Cell survival, as measured by histochemical enzyme techniques, was demonstrated in all fresh grafts and in those stored in nutrient medium but was absent in beta-propiolactone treated grafts. In instances where fresh allografts were used, histochemical techniques revealed marked diminution or absence of enzymatic activity in the aortic wall corresponding to areas of cellular depletion seen with other stains (Figs 3 and 4). Focal intimal proliferation, observed in seven puppies, appeared as accumulations of uniform and loosely arranged spindle cells as early as 16 days after allograft insertion (Fig. 2).

Changes in the elastic fibres of the aortic wall were noted in grafts as early as four days and became more pronounced with longer durations; wider spacing and fragmentation appeared to be the early changes (Fig. 5). These were followed by a linear focal deposition of calcium. In contrast to the gross findings, microscopic evidence of calcification was present as early as 16 days after the operation (Fig. 6). Calcium deposits were observed to spare the intimal aspect of the aortic wall (Fig. 7). The calcium was generally readily visualized with routine stains, but special stains, such as von Kossa and alizarin, made the deposits more easily recognizable in cases of minimal in. volvement (Figs 8 and 9). Stains for iron were negative. A conspicuous finding was the absence of calcification in areas of the aortic wall or cusp which retained their cellularity.

The base of the allograft aortic ring was markedly thickened by fibrous tissue frequently containing irregular foci of calcification (Fig. 7). Inflammatory cell reaction was most visible in the anastomotic areas with lesser degrees in the aortic adventitia.

\section{DISCUSSION}

Our experimental study has allowed us to detect the origin and progression of degenerative changes. The study of these allografts in growing puppies, in whom the degenerative tissue changes occur at an accelerated pace, has made this type of animal model quite adequate to determine the mechanism of failure of allograft valved conduits in the RVOT location.

The rationale behind the three methods of preparation used was as follows: In group A, fresh allografts assured the implantation of viable grafts. The evaluation of findings in group $B$ is especially pertinent since, in clinical practice, this appears to be the most practical method of establishing allograft banks. Group $C$ was used as a control because beta-propiolactone renders the tissues non-viable. Although the calcification was observed in all three groups, it was most marked in group $\mathrm{C}$ animals.

Calcification began in those areas of the graft with no evidence of viability, namely, the outer portions of the aortic wall. It was only occasionally present in the valve leaflets and then to a minimal degree. In groups $\mathbf{A}$ and $\mathbf{B}$, cells persisted in the inner third of the aortic wall as if they were able to survive by having adequate availability from the blood stream. These cells were metabolically active, as shown by histochemical enzyme strains. Diminution or absence of enzymatic activity correlated with areas of cell depletion.

These findings again point out that cell viability is perhaps the most important factor determining durability and long-term function of the grafts. This statement is supported by good longterm results obtained with fresh allografts in the RVOT location (Moore et al., 1976) and viable 
allograft replacement of the aortic and mitral valves (Barratt-Boyes et al., 1969; Angell, Shumway, and Kosek, 1972; Gonzalez-Lavin and O'Connell, 1973; Moore et al., 1975).

The exact mechanism of allograft calcification is not known. Urist and Adams (1967) have discussed the role of biochemical derangement and allograft damage. The morphological changes detected in the allograft in the RVOT have been described by many authors investigating the behaviour of arterial allografts in various parts of the vascular system (Coleman, Deterling, and Parshley, 1955; Halpert et al., 1960; Szilagyi et al., 1970).

\section{CONCLUSION}

Our study supports the suspected mechanism of failure of these valved conduits. The initial prerequisite is the lack of viability of the tissue with disappearance of cells, followed by degenerative changes and alteration of the normal architecture of the tissue. The area where most degenerative changes begin is the aortic wall near the sinus of Valsalva. From there calcium deposits appear at the base of the leaflets, altering their function and producing increasing turbulence of the blood stream, which in time may promote the development of more calcification in the area.

In the light of these studies, coupled with clinical experience, one can foresee a better long-term functional result by adopting certain measures, namely, using a viable allograft valve, trimming most of the excess aortic wall (thus necessitating the use of a prosthetic conduit), and, finally, using a flexible frame to stabilize the proximal anastomosis where necrosis and calcification will always occur.

\section{REFERENCES}

Angell, W. W., Shumway, N. E., and Koseck, J. C. (1972). A five-year study of viable aortic valve homografts. Journal of Thoracic and Cardiovascular Surgery, 64, 329.

Barratt-Boyes, B. G., Roche, A. H. G., Brandt, P. W. T., Smith, J. C., and Lowe, J. B. (1969). Aortic homograft replacement: a long-term follow-up of an initial series of 101 patients. Circulation, 40, 763.

Coleman, C. C., Jr., Deterling, R. A., Jr., and Parshley, M. S. (1955). Some long-term observations on aortic homografts. Surgery, 37, 64.
Fine, G., Morales, A., and Scerpella, J. R. (1966). Experimental myocardial infarction: a histochemical study. Archives of Pathology, 82, 4.

Fontan, F. and Baudet, E. (1971). Surgical repair of tricuspid atresia. Thorax, 26, 240.

Gonzalez-Lavin, L. and O'Connell, T. X. (1973). ®ొ Mitral valve replacement with viable aortic homograft valves. Annals of Thoracic Surgery, 15, 592. ?

Halpert, D., De Bakey, M. E., Jordan, G. L., Jr., and $\overrightarrow{\vec{H}}$ Henly, W. S. (1960). The fate of homografts and $\stackrel{\leftrightarrow}{\omega}$ prostheses of the human aorta. Surgery Gyne- $\overrightarrow{\vec{x}}$ cology and Obstetrics, 111, 659.

Kaplan, S., McKinivan, C. E., Helmsworth, J. A., $\stackrel{\omega}{\omega}$ Benzing, G., Schwartz, D. C., and Schreiber, J. T. के (1974). Complications following homograft re- placement of the right ventricular outflow tract. जु Annals of Thoracic Surgery, 18, 250.

McGoon, D. C., Wallace, R. B., and Danielson, G. K. (1973). The Rastelli operation: its indications $\vec{\square}$ and results. Journal of Thoracic and Cardiovas- $\mathbb{D}$ cular Surgery, 65, 65.

Merin, G. and McGoon, D. C. (1973). Reoperation 3 after insertion of aortic homograft as a right $\mathbb{D}$ ventricular outflow tract. Annals of Thoracic Surgery, 16, 122.

Moore, C. H., Martelli, V., Al-Janabi, N., and Ross, के D. N. (1975). Analysis of homograft valve failure o in 311 patients followed up to 10 years. Annals of Thoracic Surgery, 20, 274.

Moore, C. H., Martelli, V., and Ross, D. N. (1976). Reconstruction of right ventricular outflow tract $\%$ with a valved conduit in 75 cases of congenital $\stackrel{\perp}{\perp}$ heart disease. Journal of Thoracic and Cardio- $\Rightarrow$ vascular Surgery, 71, 11.

Park, S. C., Neches, W. H., Lenox, C. C., Zuberbuhler, J. R., and Bahnson, H. T. (1973). Massive calcification and obstruction in a homograft after the Rastelli procedure for transposition of great arteries. American Journal of Cardiology, 32, 860.

Ross, D. N. and Somerville, J. (1966). Correction of $\underset{x}{\stackrel{2}{~}}$ pulmonary atresia with a homograft aortic valve. $-\dot{\sigma}$ Lancet, 2, 1446.

Szilagyi, D. E., Rodriguez, F. J., Smith, R. F., and Elliot, J. P. (1970). Late fate of arterial allografts. Archives of Surgery, 101, 721.

Urist, M. R. and Adams, J. M., Jr. (1967). Localiza- $\frac{\bigcirc}{\partial}$ tion mechanism of calcification in transplants of $D$ aorta. Annals of Surgery, 166, 1.

Requests for reprints to: Dr. Lorenzo Gonzalez Lavin, Professor and Chief, Division of Cardiothoracioe Surgery, Michigan State University, 111 Giltner Hall, East Lansing, MI 48824, USA. 